
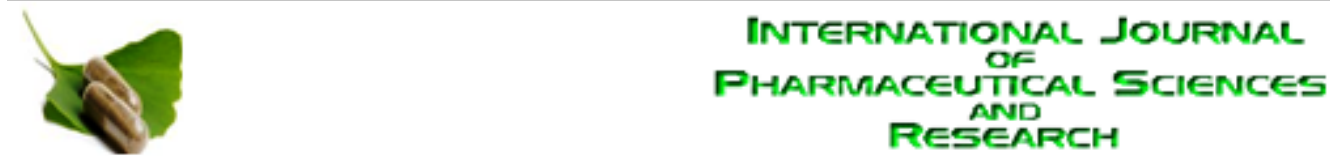

Received on 27 October, 2011; received in revised form 17 December, 2011; accepted 17 February, 2012

\title{
PROBIOTICS, PREBIOTICS AND SYNBIOTICS
}

Sweta V. Chauhan* and Mehul R. Chorawala

Dept. Of Pharmacology, K.B.Institute of Pharmaceutical Education and Research, Gh-6, Sector-23, Gandhinagar382023, Gujarat

Keywords:
Probiotics,
Prebiotics, S
ynbiotic,
Bifidobacteria,
Lactobacilli
uhan
macology, K.B.Institute of
al Education and Research,
23, Gandhinagar-382023,
Gujarat

\begin{abstract}
The benefits of Probiotics have been recognized and explored for over a century. Probiotics consist of bacteria or yeasts and can be considered functional foods that can re-colonize and restore the microflora symbiosis of the intestinal tract. Several health benefits associated with the Probiotics in various diseases includes Inflammatory Bowel Disease (IBD), Colon Cancer, Rotavirus-associated diarhoea, H.Pylori infection and Liver disease etc. Prebiotics are "non-digestible food ingredients that beneficially affect the host by selectively stimulating the growth and/or activity of one or a limited number of bacteria in the colon". Dietary modulation of the gut microflora by Prebiotics is designed to improve health by stimulating numbers and/or activities of Probiotics like Bifidobacteria and Lactobacill.This review also discuss the results of randomized controlled clinical trials that used Prebiotics to treat IBD, Hypertension, Colon Cancer, Diabetes and Hepatic Encephalopathy as well as their potential applications. The combination of Probiotics and Prebiotics is known as Synbiotics. Recently Synbiotics have been proposed as a new therapeutic option in Pediatric surgery, Digestive organ surgery, Liver disease and Systemic Inflammatory Response Syndrome (SIRS). This article provides the overview of how Pro-, Pre- and Synbiotics contribute towards various health benefits.
\end{abstract}

\section{INTRODUCTION:}

Probiotics: Probiotics were first described by Metchnikoff in 1908 based on his observations on the longevity of individuals who lived in a certain part of Bulgaria and which he attributed to their ingestion, on a regular basis, of a fermented milk product. Probiotics, derived from the Greek and meaning "for life", are defined as live organisms that, when ingested in adequate amounts, exert a health benefit to the host ${ }^{1}$. There are several commercially available supplements containing viable micro-organisms with probiotic properties.

There are several criteria for organisms as Probiotics include: It should be isolated from the same species as its intended host, Have a demonstrable beneficial effect on the host, non-pathogenic, and be able to survive transit through the gastrointestinal tract ${ }^{2}$, large number of viable bacteria must be able to survive prolonged periods of storage ${ }^{3,4}$.

Examples of Probiotics are shown in Table 1. 
TABLE 1: ORGANISMS AS PROBIOTICS $5,6,7$
L. casei $D 12$
L. casei F19
L. casei Nikka
L. casei $61 R 3$
L. casei $\mathrm{CHCC} 3137$
L. casei $8 R 2$
L. acidophilus NCFM
L. acidophilus $X 37$
L. gasseri 123
L. paracasei $A 14$
L. paracasei $B 32$
L. paracasei CRL431
L. paracasei Q85
L. paracasei Z11
L. salivarius
L. helviticus
L. paraplantarum D14
L. plantarum $299 \mathrm{~V}$
L. plantarum M.1.1
B. breve
Lactococcus lactis
Bacillus clausii
Bacillus coagulans
B. bifidum DSM20239
B. bifidum $Z 9$
B. breve DSM20091
B. breve DSM20213
B. longum subsp. infantis 20088
L. rhamnosus 19070-2
L. rhamnosus E5
L. rhamnosus $G 26$
L. rhamnosus $G G$
L. ruminus $Q 95$
L. delbrueckii subp Bulgaricus
L. brevis
L. cellobiosus
L. curvatus
L. johnsonii
L. farciminis
L. fermentum
B. bifidum $B b-14$
B. bifidum DSM20082
Streptococcus thermophilus
Escherichia coli Nissle 1917
Bacillus oligonitrophilis
B. longum Q45
B. longum Q46
B. longum Q50
B. longum Z8
B. animalis subsp. lactis Bb 12
B. longum M.16.2
B. breve M.97.2
B. longum ssp. infantis $P 30.5$
B. bifidum S.13.1
B. infantis
B. thermophilum
B. adolescents
B. lactis
B. animalis
Enterococcus faecium
Propionibacterium freudenreichii
Saccharomyces cerevisiae
Saccharomyces boulardii

Criteria for the use of Probiotics in humans ${ }^{\mathbf{8}}$ : Identified at the genus, species, and strain level, safe for food and clinical use (nonpathogenic, susceptible to antibiotics), able to survive intestinal transit, able to adhere to mucosal surfaces, able to colonize the human intestine or vagina (at least temporarily), producing antimicrobial substances, able to antagonize pathogenic bacteria, clinically documented and validated health effects.

Prebiotics: Prebiotics are "non-digestible food ingredients that beneficially affect the host by selectively stimulating the growth and/or activity of one or a limited number of bacteria in the colon" 9 . For a dietary substrate to be classed as prebiotic, criteria required are ${ }^{10}$ :
The substrate must not be hydrolyzed or absorbed in the stomach or small intestine; it must be selective for beneficial commensal bacteria in the large intestine such as the bifidobacteria, Fermentation of the substrate should induce beneficial luminal/systemic effects within the host.

The rationale behind prebiotic use is to elevate the endogenous numbers of beneficial bacterial strains including lactobacillus and bifidobacterium ${ }^{11}$. This increase will impart the beneficial effects seen by probiotic administration, including an increase in SCFA production, particularly butyrate, which can provide fuel for enterocytes, prevention of pathogenic adherence, production of anti-bacterial substances, and decreased luminal $\mathrm{pH}^{12}$. Examples of Prebiotics are shown in Table 2.

TABLE 2: SUBSTRATES AS PREBIOTICS ${ }^{13,14,15}$

\begin{tabular}{ccc}
\hline $\begin{array}{c}\text { Inulin (legumes, vegetables } \\
\text { and cereals) }\end{array}$ & $\begin{array}{c}\text { Fructo- oligosaccharides - FOS (legumes, vegetables, } \\
\text { cereals) }\end{array}$ & $\begin{array}{c}\text { Xylo-oligosaccharides (plant } \\
\text { sources) }\end{array}$ \\
\hline $\begin{array}{c}\text { Resistant starches (legumes, vegetables and } \\
\text { cereals) }\end{array}$ & $\begin{array}{c}\text { Soybean oligosaccharides } \\
\text { (soy bean) }\end{array}$ & $\begin{array}{c}\text { Trans Galacto-oligosaccharides } \\
\text { (lactose synthetic) }\end{array}$ \\
\hline Lactulose (lactose synthetic) & Lactitol (lactose synthetic) & Goat's milk oligosaccharides \\
\hline
\end{tabular}


Germinated Barley Foodstuff (High glutamine

rich protein $\&$ hemi-cellulose-rich dietary fiber)
Human breast milk oligosaccharides

Isomalto-oligosaccharides

Raffinose
Synbiotics: Synbiotics refer to nutritional supplements combining Probiotics and Prebiotics that are thought to act together; i.e. synergism. It has been suggested that a combination of a probiotic and a prebiotic, i.e. Synbiotics, might be more active than either a probiotic or prebiotic alone in preventing GI Disorders 16,17 . The potential benefits of synbiotic therapy are obvious, however, the great challenge, as is the case with Probiotics and Prebiotics alone, is to determine the best combination for each disease setting and each individual.

The first attempts should be to combine Probiotics and Prebiotics which have demonstrated individual benefits to determine if there are additive effects, alternatively, a more structured approach would be to determine the specific properties that a prebiotic requires to be beneficial to the probiotic and select the prebiotic accordingly ${ }^{18}$.

Example of Synbiotics includes ${ }^{19}$ : Bifidobacteria + Fructo-oligosaccharides, Lactobacilli + Lactitol, Bifidobacteria + Galacto-oligosaccharides

\section{Probiotics \& Health Benefits:}

Inflammatory Bowel Disease: Inflammatory bowel disease (IBD) comprises a spectrum of disorders characterized by inflammation, ulceration and abnormal narrowing of the gastrointestinal tract resulting in abdominal pain, diarrhoea and gastrointestinal bleeding ${ }^{20}$. The role of intestinal microorganisms as the mediators of this intestinal inflammation is supported by a number of clinical findings.

A number of investigators have used Probiotics in patients with IBD. In 1997, Kruis et al., randomized 103 patients with inactive ulcerative colitis to receive a non-pathogenic E. coli or Mesalazine for 12 weeks ${ }^{21}$. Malin and colleagues administered Lactobacillus GG to 14 children with Crohn's disease and demonstrated enhanced serum IgA levels, suggesting immunostimulation.
Probiotics have also been used in chronic relapsing pouchitis ${ }^{22}$. Gienchitto and colleagues prescribed a mixture of eight different probiotic strains to twenty patients with pouchitis ${ }^{23}$. Several in vitro studies on cell models of IBD have shown the ability of certain probiotic strains such as L. rhamnosus GG to modulate the immune system by down regulating TNF-a-induced IL-8 production ${ }^{24}$. In vivo animal studies have indicated the importance of commensal bacteria in the development of a functional immune system. B. lactis Bb12 initially elevated levels of IL- 6 expression, but rats maintained normal gut histology ${ }^{25}$. Several studies have shown that Probiotics might have had beneficial effect on IBD patients.

Alleviation of Lactose Intolerance: Lactose upon ingestion is hydrolyzed by lactase in the brush border membrane of the mucosa of the small intestine into constitutive monosaccharides, glucose and galactose, which are readily absorbed in the blood stream. However, the activity of intestinal lactase in lactose intolerant individuals is usually less than $10 \%$ of childhood levels ${ }^{26}$. This decline, termed hypolactasia, causes insufficient lactose digestion in the small intestine, characterized by an increase in blood glucose concentration or hydrogen concentration in breath upon ingestion of $50 \mathrm{~g}$ lactose, conditions designated as lactose maldigestion ${ }^{27}$.

Probiotics have been shown to improve lactose digestion by reducing the intolerance symptoms as well as by slowing orocecal transit ${ }^{28}$.

Pediatric Intestinal Disease: Breastfed babies have a predominant colonization with E. coli and Streptococci bifidobacteria, while those fed with formula milk have microbiotas with predominance of bifidobacteria, bacteroidi, clostridia and other enterobacteria. The gradual establishment of the flora from the early hours of life allows modulating the immune response in favor of the acquisition of oral tolerance ${ }^{29,30}$, defined as "specific immunological hyporesponse to a previous exposure to mucosal antigen". 
Infants who are fed with formula milk supplemented with probiotic bacteria may experience promotion of the natural production of this immunoglobulin. Supplementation with Probiotics is generally considered safe because they are identical to the microorganisms present in vaginal flora and in the human gastrointestinal tract ${ }^{31}$.

Necrotizing Enterocolitis: Necrotizing enterocolitis (NEC) is a major cause of morbidity and mortality in premature infants; the etiology of this disease has not yet been fully clarified. Based on observations in animal models, some studies evaluated the effects of Probiotics supplementation on the incidence of NEC in newborns. A recent review examined the results of 11 studies, showing that the risk of NEC and death in the population treated with Probiotics is lower and confirming significant benefits of a supplementation with Probiotics in premature and very-low birth weight infants $^{32}$.

Infantile Diarrhoea: Rotavirus is the most common cause of acute childhood diarrhea in the world and is an important cause of infant mortality. This condition is generally self-limiting and treatment is supportive, with careful replacement of fluid and electrolyte losses. In a study of 100 children, admitted to hospital with acute diarrhea, Guarino demonstrated a reduced duration of diarrhea in children receiving Lactobacillus GG (3 days) compared with controls (6 days) ${ }^{33}$. Probiotic therapy has been aimed at the treatment of established rotaviral infections in children and also in prevention of the disease.

The potential benefit of probiotics in the treatment of rotavirus infection appears, however, to be a strain related phenomenon. In summary, there is good evidence to support the use of Probiotics in patients with infantile diarrhea ${ }^{2}$.

Traveller's Diarrhoea: Diarrhoeal illness is common in travellers. Bacterial infections with enterotoxigenic Escherichia coli, Shigella species, Campylobacter jejuni and Salmonella cause at least $80 \%$ of traveller's diarrhoea ${ }^{34}$. A wide variety of Probiotics have been used to treat or as prophylaxis against diarrhoea with varying results. Trevis capsules, containing Lactobacillus acidophilus, Bifidobacterium bifidum, Lactobacillus bulgaricus and Streptococcus thermophilus were administered to 195 Danish tourists in Egypt and conferred a protection rate of 39\% against diarrhoea ${ }^{35}$. Given the contrary nature of these results, it is difficult to advocate the use of Probiotics in travelers at the present time.

Antibiotic Associated Diarrhoea: The use of antibiotics is widespread and is often associated with gastrointestinal side effects such as diarrhoea. Pseudomembranous colitis is a serious, occasionally fatal, complication of antibiotic therapy which is characterized clinically by profuse diarrhoea, toxemia and 'pseudomembrane' formation at sigmoidoscopy ${ }^{36}$. Many Probiotics have been employed in the treatment of antibiotic related and clostridial diarrhoea, with variable results. A recent study in 188 children who received oral antibiotics for acute infectious disorders, also demonstrated decreased stool frequency when Lactobacillus GG was given concomitantly ${ }^{37}$. Notwithstanding the encouraging results demonstrated with the use of Lactobacillus GG the routine clinical use of Probiotics for all cases of antibiotic related diarrhoea cannot be justified at present.

Food Allergy Reaction: Human beings are exposed to numerous environmental antigens through food. The intestinal mucosa is efficient in assimilating antigens encountered by the enteric route, but high-level antigen exposure during the first few months of life may pre dispose individuals to allergic sensitization ${ }^{38}$. Oral introduction of Probiotics can help in treatment of such food allergies by alleviating intestinal inflammation. It has also been suggested that intestinal microorganisms could down-regulate the allergic inflammation by counter-balancing T-helper cell Type 2 responses and by enhancing antigen exclusion through induction of an IgA response ${ }^{39}$. Majamaa and Isolauri suggest that probiotic bacteria may promote endogenous barrier mechanisms in the patients with atopic dermatitis and food allergy ${ }^{40}$.

Immunomodulatory activity: Immunomodulation by Probiotics is a subject of growing interest. Lactobacillus rhamnosus GG and Propionibacterium freudenreichii ssp. shermanii JS have shown a specific dose- and duration-dependent Immunomodulatory effects on the proliferative activity of murine $B$ and $T$ lymphocytes ${ }^{41}$. 
In another study the effects of heat-killed cells, cell walls, and cytoplasmic extracts of Bifidobacterium, Lactobacillus acidophilus, L. bulgaricus, L. casei, $L$. gasseri, L. helviticus, L. reuteri, and Streptococcus thermophilus, on cell proliferation and cytokine and nitric oxide (NO) production, were examined using the RAW 264.7 macrophage cell line and in murine cultures composed of peritoneal, spleen, and Peyer's patch cells.

Oral administration of Bifidobacterium breve YIT4064 has been reported to activate the humoral immune system by augmenting anti-rotavirus IgA production or anti-influenza virus, IgG production, and thus protect against rotavirus infection or influenza infection, respectively ${ }^{42}$.

\section{Hypocholesterolemic effects: The hypochole-} sterolemic effects of Probiotics are the subject of controversy. Studies published in the 1970s and 1980s consistently reported $5-17 \%$ reductions in serum cholesterol concentrations after 2-4 wk of daily consumption of fermented milk products, but these data have been challenged by the results of more recent studies, almost all of which did not report any significant effect ${ }^{28}$.

The administration of Lactobacillus reuteri CRL 1098 (10 cells /day) to hypercholesterolemic mice for 7 days decreased total cholesterol by $38 \%$, producing serum cholesterol concentrations similar to that of the control group. This dose of Lactobacillus reuteri caused a $40 \%$ reduction in triglycerides and a $20 \%$ increase in the ratio of high density lipoprotein to low density lipoprotein without bacterial translocation of the native microflora into the spleen and liver ${ }^{43}$.

\section{Anti-mutagenic, Anti-genotoxic \& Anti-carcinogenic} activity: Antigenotoxicity, antimutagenicity and anticarcinogenicity are important potential functional properties of Probiotics, which received much attention recently. Mutagens are frequently formed during stress or due to viral or bacterial infections and phagocytosis but also commonly obtained via foods. Endogenous DNA damage is one of the contributors to ageing and age-related degenerative diseases. Some epidemiological researchers have emphasized that probiotic intake may be related to a reduced colon cancer incidence ${ }^{44}$ and experimental studies showed the ability of lactobacilli and bifidobacteria to decrease the genotoxic activity of certain chemical compounds 45 and increase in antimutagenic activity during the growth in selected media ${ }^{46}$.

Antimutagenic effect of fermented milks has also been detected against a range of mutagens and promutagens including 4-nitroquinoline-NO-oxide, 2nitrofluorene, and benzopyrene in various test systems based on microbial and mammalian cells. Experiments carried out in animal models showed certain strains of L. acidophilus and Bifidobacterium spp. was capable of decreasing the levels of enzymes such as bglucuronidase, azo reductase, and nitroreductase responsible for activation of procarcinogens.

This inactivation consequently led to a substantial decline of the risk associated with tumor development. Several studies have shown that preparations containing $L A B$ inhibit the growth of tumor cells in experimental animals or indirectly lower carcinogenicity by decreasing bacterial enzymes that activate carcinogenesis ${ }^{47}$. Short-chain fatty acids produced by $\mathrm{L}$. acidophilus and bifidobacteria were also reported to inhibit the generation of carcinogenic products by reducing enzyme activities.

Probiotics and Sepsis in surgical and critically ill patients: Septic complications in surgical and intensive care patients are common. The majority of Nosocomial infections are caused by intestinally derived organisms such as $E$ coli ${ }^{48}$. There is increasing evidence to suggest that passage of these organisms across the intestinal barrier to normally sterile extra intestinal sites may be the cause of this septic morbidity. In the elective group, 64 patients were randomized to receive the Lactobacillus plantarum 299v in a fruit drink (Proviva ${ }^{\mathrm{TM}}$ ) for one week pre-operatively with 65 controls.

At the beginning of the trial, no prophylactic antibiotics were given to the probiotic group at the induction of anesthesia. The rate of bacterial translocation to mesenteric lymph nodes and serosa was documented as was the incidence of septic complications. In the intensive care unit, 45 critically ill patients were randomized to receive Lactobacillus plantarum $299 \mathrm{v}$ and compared with 45 controls. The rate of infective complications and clinical outcome were unchanged, however CRP and IL- 6 levels and endotoxin exposure 
did tend to be lower in the probiotic group, just failing to reach statistical significance. These findings suggest that Probiotics may modulate barrier function when it is deficient, but not when it is undisrupted, as in the elective situation above ${ }^{2}$.

Inhibition of Helicobacter pylori and other intestinal pathogens: Probiotic cultures produce a wide range of antibacterial compounds including organic acids (e.g., lactic acid and acetic acid), hydrogen peroxide, bacteriocins, various low-molecular mass peptides, and antifungal peptides/proteins, fatty acids, phenyllactic acid, and $\mathrm{OH}$-phenyllactic acid. Lactic and acetic acids are the main organic acids produced during the growth of Probiotics and their $\mathrm{pH}$ lowering effect in the gastrointestinal tract has a bactericidal or bacteriostatic effect.

Moreover, a heat-stable, low- molecular- weight antibacterial substance different from lactic acid was present in the cell-free culture supernatant resulting in the inactivation of a wide range of Gram-negative bacteria and inhibition of the adhesion to and invasion of Caco-2 cells by Salmonella enteric ser. typhimurium 49, 50. Helicobacter pylori are an intestinal pathogen, long-term infection by which leads to chronic gastritis, peptic ulcer and increases the risk of gastric malignancies ${ }^{51}$. Probiotic organisms do not appear to eradicate $H$. pylori, but they are able to reduce the bacterial load and inflammation in animal and human studies. It has been suggested that the suppression effect is strain dependent ${ }^{52}$. L. casei Shirota strain showed a significant reduction in the levels of $\mathrm{H}$. pylori colonization in the antrum and body mucosa in vivo mouse model ${ }^{53}$.

Recent study concluded that regular intake of yogurt containing B. animalis Bb12 and L. acidophilus La5 may effectively suppress $H$. pylori infection in humans ${ }^{54}$. In the other studies in humans treated either with lyophilized culture of L. brevis ${ }^{55}$ or yogurts containing L. acidophilus and B. lactis ${ }^{54}$ or L. johnsonii La1 ${ }^{56,}$ a decrease in the $H$. pylori bacteria load was observed indirectly via the urea breath test.

Respiratory Infections: All Probiotics induce an immune response, whose characteristics are related to the strain or the combination of bacteria that have been used. Recent studies have shown positive effects of Probiotics on the respiratory system, especially in preventing and reducing the severity of respiratory infections, due to an increase in IgA-secreting cells in the bronchial mucosa ${ }^{57}$. Hereafter, we present the results of studies performed on different target populations aimed at investigating the effects of Probiotics on infectious diseases of the respiratory system.

Irritable Bowel Syndrome: The pathogenesis of irritable bowel syndrome remains unknown, and abnormal neural activation, neural innervations, or abnormal innate immune responses have all been implicated. The therapy of irritable bowel syndrome has remained largely unsatisfactory. Against this background, there have been attempts to evaluate a role for Probiotics in the therapy of patients with irritable bowel syndrome.

Several recent meta-analyses have examined the evidence for benefit from Probiotics in irritable bowel syndrome ${ }^{58}$ in all analyses, it appeared that Probiotics were associated with a modest benefit (approximately 20-24\%) compared to placebo. These were short term studies, and since irritable bowel syndrome requires long term therapy whether Probiotics will provide sustained clinical benefit over longer periods of time, and whether they are useful in specific sub-groups, needs to be evaluated.

Liver disease: In recent years, it has been recognized that several of the manifestations of chronic liver disease including encephalopathy, endotoxemia and bacterial peritonitis have primary origins in the gut through translocation of molecules or bacteria past the intestinal barrier. Probiotics enhance intestinal barrier function; they also influence innate immune activity and adaptive immunity.

Probiotics have therefore been tried in the therapy of chronic liver disease. Small pilot studies or open label studies suggest that Probiotics may benefit patients with non-alcoholic steato-hepatitis, alcoholic liver disease, and minimal hepatic encephalopathy and lowers endotoxemia in liver cirrhosis 59, 60. These findings need to be confirmed in large randomized trials before a place can be established for the use of Probiotics in chronic liver disease. 
Urogenital Infections: Urogenital infections not caused by sexual transmission in women are still one of the most important medical issues. Recurrent urinary tract infection (UTI) is, in most cases caused by the uropathogens E. coli; recurrent bacterial vaginosis (BV) is usually caused by Gardnerella vaginalis; recurrent yeast vaginosis is usually caused by Candida albicans. The predominant bacteria in the urinary tract of healthy women are lactobacilli. Zuccotti et al., reported some studies highlighting that Probiotics could be a good alternative to antibiotic therapy due to their quality to adhere to uroepithelial cells and produce inhibitors of pathogenic growth and biosurfactant secretion ${ }^{61}$.

Reid et al., reported that a daily intake of probiotic strains L. rhamnosus GR-1 and Lactobacillus fermentum RC-14 resulted in some asymptomatic BV patients reverting to a normal lactobacilli dominated vaginal microflora ${ }^{62}$. They reported a crossover study involving 33 patients with recurrent vaginitis treated with eight ounces of L. Acidophilus supplemented yogurt daily for six months and then switched to a yogurt free diet. Czaja et al., performed a phase I trial to assess the safety and tolerance of a Lactobacillus vaginal suppository for prevention of recurrent UTI involving premenopausal women with a history of recurrent $\mathrm{UTI}^{63}$.

Pancreatitis: Pancreatic necrosis and associated pancreatic infection are determinates of poor outcome in patients with severe acute pancreatitis, and the nature of microbial species inhabiting the intestine can influence subsequent infection rates. Two small randomized double-blind trials have been published by the same research group examining the effect of nasojejunal treatment with Lactobacillus plantarum in patients with acute pancreatitis 64,65 . Both trials compared live L. plantarum with killed bacteria as a control, and both showed significantly lower rates of infection in the groups treated with the live probiotic. Replication of these results, ideally in larger studies, would provide excellent evidence for probiotic use in this setting.

Clinical studies on Probiotics: A randomized, doubleblind, placebo-controlled trial was performed to determine whether Probiotics may reduce the risk of infections in infants. The children involved in the research were younger than 2 months of age and were daily provided with milk containing L. rhamnosus GG and Bifidobacterium lactis Bb-12, or placebo milk, administered until 12 months of age. The results suggest that Probiotics may represent a mean to reduce the risk of early acute otitis media and the use of antibiotics for recurrent respiratory infections during the first year of life ${ }^{66}$.

Similar results have emerged in a study performed on a target population of 326 children aged between 3 and 5 years, showing more than 65\% decrease in the incidence of antibiotic use and $25 \%$ reduction in school missed days among children treated with Probiotics ${ }^{67}$.

A randomized double-blind, placebo-controlled trial assessed whether the consumption for 3 months of Lactobacillus gasser PA 16/8, Bifidobacterium longum SP $07 / 3$, B. bifidum MF $20 / 5$, had impacts on symptoms severity, incidence and duration of common cold. Similar conclusions were obtained in a study that assessed the effect of long-term intake of Probiotics on the same pathology ${ }^{68}$.

Two multicentre, randomized, controlled, double-blind studies were conducted in two successive vaccine seasons (pilot study and control). 86 and 222 elderly volunteers consumed, respectively, a fermented milk drink containing L. casei DN-114 001, a fermented yogurt or a control unfermented dairy product, twice a day for a period of 7 or 13 weeks. Vaccination took place after 4 weeks. The study showed that Probiotics improve antibody responses to influenza vaccination in individuals over 70 years ${ }^{69}$. L. casei DN-114001 was also evaluated in a multicentre, double-blind, controlled study on 1.072 elderly, to assess the resistance to respiratory infections. The product containing Probiotics, well tolerated, induced a reduction in the duration of respiratory infections, especially URTI and nasopharyngitis ${ }^{70}$.

\section{Recombinant Probiotic:}

Subalin: A new probiotic class based on recombinant strains of bacteria has been designed to produce predetermined therapeutic proteins. The biological properties of Bacillus subtilis 2335 strain were transformed by the plasmid encoding the synthesis of human interferon alpha- 2 . The recombinant strain was demonstrated to preserve the high antagonistic 
activity of the parent culture (biosporin) and to acquire marked antiviral properties due to interferon synthesis. Using this strain, Sorokulova et al., designed the new probiotic possessing a combination of antibacterial and antiviral properties ${ }^{71}$. Clinical and bacteriological investigations during administration and after termination of the course of oral administration of subalin have suggested innocuousness as well as to the absence of any sideeffects of subalin ${ }^{72}$. Both biosporin and subalin have been proven to be safe when injected intravenously and intraperitoneally into animals at a dose of 5310 cells per $0.5 \mathrm{ml}$ of physiological saline ${ }^{73}$.

Subalin has been tested for its ability of increasing the effectiveness of anti-tumor therapy with cyclophosphamide. Furthermore, the application of gene engineering methods may aid in designing a new generation of Probiotics with predict able biological properties.

\section{Prebiotics \& Health Benefits:}

Inflammatory Bowel Diseases: In Experimental colitis, Studies using Prebiotics have been performed mostly in animal models. Lactulose and Inulin have been shown to attenuate inflammation in IL-10 knockout mice and DSS-induced colitis respectively ${ }^{74,75}$. The combination of Inulin and oligofructose (mixture 1:1) is also effective in preventing the development of colitis in HLA-B27 transgenic rats ${ }^{76}$. This beneficial effect is observed in conjunction with an increase of intestinal bifidobacteria and lactobacilli. DSS-induced colitis rats fed with goat's milk oligosaccharides maintain their body weight, have reduced colonic Myeloperoxidase activity and clinical symptoms and increased MUC-3 expression compared with control rats ${ }^{77}$. Lactulose has also demonstrated a dose-dependent beneficial effect on DSS induced colitis in rats, including improvements of colonic ulceration areas, body weight changes, diarrhea, bloody stools and a reduction of Myeloperoxidase activity and Microscopic colitis ${ }^{78}$.
Several studies have investigated the use of an insoluble mixture of glutamine-rich protein and hemicellulose-rich dietary fiber termed germinated barley foodstuff (GBF). Fukuda et al found that feeding GBF to rats with DSS induced colitis results in significantly reduced colonic inflammation scores, and increased butyrate concentrations in cecal contents ${ }^{79}$.

In Ulcerative colitis, although there is a paucity of human studies using Prebiotics, but the few emerging studies showed that there is potential for this treatment modality. A multi-centered open-label trial reported that oral administration of GBF to patients with mild to moderately active UC for $24 \mathrm{wk}$ results in a significant decrease in clinical activity index, compared to controls ${ }^{80}$. An open-label study of 22 UC patients in remission showed that a daily oral intake of $20 \mathrm{~g}$ GBF results in a significantly improved clinical activity index and endoscopic score at 3, 6 and $12 \mathrm{mo}$, and a reduced relapse rate, compared with controls ${ }^{81}$.

A small, uncontrolled study of 15 active Crohn's disease patients reported that $21 \mathrm{~d}$ of Fructooligosaccharide $(15 \mathrm{~g})$ intake results in a significant decrease of disease activity, an increase of intestinal bifidobacteria and modifications of Toll-like receptors and IL-10 expression in mucosal dendritic cells ${ }^{82}$.

Antihypertensive effects: Hypertension is one of the major risk factors for cardiovascular disease. Dietary components including Prebiotics are seen as better alternatives than drug therapy to treat hypertension considering that Prebiotics has a long history of safe use and has been a natural component present in our foods. Plant fibers are also found to exert prebiotic properties, health enhancing effects and strongly influence the metabolism of carbohydrates and lipids, which are directly associated with the increased risks of hypertension. Direct association of Prebiotics and antihypertension has been established via various invivo trials which is shown in following table 3.

TABLE 3: VARIOUS IN-VIVO TRIALS SHOWING ASSOCIATION BETWEEN PREBIOTICS \& THEIR ANTI-HYPERTENSIVE ACTIVITY

\begin{tabular}{|c|c|c|c|c|c|}
\hline I Intervention & Experimental Design & Subjects & Dose & Effects & Ref \\
\hline $\begin{array}{l}\text { Soluble fiber } \\
\text { extracted from oat } \\
\text { bran }\end{array}$ & $\begin{array}{c}\text { Randomized, } \\
\text { double-blind, } \\
\text { placebo-controlled }\end{array}$ & $\begin{array}{l}\mathrm{n}=110 ; 30 \text { to } 65 \text { years; not on } \\
\text { hypertension treatment; SBP of } 125-159 \\
\mathrm{mmHg} \text { and DBP of }<95 \mathrm{mmHg}\end{array}$ & $\begin{array}{c}8 \mathrm{~g} / \mathrm{d} \text { of fiber for } \\
12 \text { weeks }\end{array}$ & $\begin{array}{c}\text { A reduction in } \\
\text { SBP of } 2 \mathrm{mmHg} \& \text { DBP of } \\
1.0 \mathrm{mmHg}\end{array}$ & 83 \\
\hline
\end{tabular}




\begin{tabular}{|c|c|c|c|c|c|}
\hline $\begin{array}{l}\text { Diet containing soy } \\
\text { protein isolate \& } \\
\text { supplementation of } \\
\text { fiber extracted from } \\
\text { psyllium }\end{array}$ & $\begin{array}{l}\text { Randomized, } \\
\text { double-blind, } \\
\text { parallel }\end{array}$ & $\begin{array}{c}\mathrm{n}=36 \text {; nonsmoking men or women }>20 \\
\text { years old; on anti hypertensive drug } \\
\text { therapy for }>6 \text { months ; SBP of } 130- \\
160 \mathrm{mmHg}\end{array}$ & $\begin{array}{l}12 \mathrm{~g} \text { fiber } / \mathrm{d} \text { for } 8 \\
\text { weeks }\end{array}$ & $\begin{array}{l}\text { A reduction in } \\
\text { SBP of } 5.9 \mathrm{mmHg}\end{array}$ & 84 \\
\hline $\begin{array}{l}\text { Dietary fiber in the } \\
\text { form of pill } \\
\text { supplementation }\end{array}$ & $\begin{array}{l}\text { Randomized, } \\
\text { double-blind, } \\
\text { parallel, placebo } \\
\text { controlled }\end{array}$ & $\begin{array}{c}\mathrm{n}=63 ; 18-70 \text { yrs old; hypertensive with a } \\
\text { minimum DBP of }>90 \mathrm{mmHg}\end{array}$ & $\begin{array}{l}7 \mathrm{~g} / \mathrm{d} \text { of dietary } \\
\text { fiber for } 12 \text { weeks }\end{array}$ & $\begin{array}{l}\text { A reduction in } \\
\text { DBP of } 5 \mathrm{mmHg}\end{array}$ & 85 \\
\hline $\begin{array}{l}\text { Beta-glucan from } \\
\text { whole oats cereals }\end{array}$ & $\begin{array}{l}\text { Randomized, } \\
\text { parallel, pilot trial }\end{array}$ & $\begin{array}{l}\mathrm{n}=18 ; 27-59 \text { years old; healthy, } \\
\text { untreated hypertensive with SBP of } 130 \text { - } \\
160 \mathrm{mmHg} \text { and DBP of } 85-100 \mathrm{mmHg}\end{array}$ & $\begin{array}{l}5.52 \mathrm{~g} / \mathrm{d} \text { of beta } \\
\text { glucan for } 6 \text { weeks }\end{array}$ & $\begin{array}{l}\text { A reduction in } \\
\text { SBP of } 7.5 \mathrm{mmHg} \text { and } \\
\text { DBP of } 5.5 \\
\mathrm{mmHg}\end{array}$ & 86 \\
\hline $\begin{array}{l}\text { Bread substituted } \\
\text { with lupin kernel } \\
\text { flour }\end{array}$ & $\begin{array}{l}\text { Randomized, } \\
\text { parallel }\end{array}$ & $\begin{array}{l}\mathrm{n}=74 ; 20-70 \text { years old; overweight and } \\
\text { obese men and women with } \mathrm{BMI} \text { of } 25- \\
35 ; \mathrm{SBP}<150 \mathrm{mmHg} \text { and } \mathrm{DBP}<95 \mathrm{mmHg}\end{array}$ & $\begin{array}{c}4 \times 40 \mathrm{~g} \text { of } \\
\text { bread/d for } 16 \\
\text { weeks; Bread } \\
\text { contained } 9.5 \% \\
\text { w/w of fiber }\end{array}$ & $\begin{array}{l}\text { A reduction in SBP of } 3.0 \\
\qquad \mathrm{mmHg}\end{array}$ & 87 \\
\hline
\end{tabular}

SBP: systolic blood pressure; DBP: diastolic blood pressure

Diabetes: Hypertension is highly associated with diabetes, where a lowering in cholesterol levels and improvement of glucose levels has been found to lower blood pressure. Dietary intervention is one of the main therapies proposed to diabetics, thus Prebiotics have gained increasing attention because of their beneficial effects on lowering blood glucose. Therefore, Prebiotics could act as antihypertensive agents upon the exhibition of blood glucose lowering effects. In a study evaluating the improvement of glucose tolerance via the intake of Prebiotics, Cani et al. administered an oligofructose-supplemented diet $[10 \%(w / w)]$ to male mice for 14 weeks.
The study used 32 male mice and the results showed that mice in the group consuming diet supplemented with oligofructose had improved glucose tolerance as compared to those in the control group ${ }^{88}$ Mice on the oligofructose-supplemented diet showed normal fasting plasma insulin levels and restored glucose induced insulin secretion while the control did not. Various studies have highlighted the beneficial effects of Prebiotics on physiological conditions such as lipid and glucose profiles that are directly associated with hypertension. Hence, there is a strong basis for continuous evaluation on Prebiotics specifically aimed at utilizing longer and larger in-vivo trials.

TABLE 4: IN-VIVO TRIALS SHOWING ASSOCIATION BETWEEN PREBIOTICS \& THEIR EFFECT ON BLOOD GLUCOSE PROFILE

\begin{tabular}{|c|c|c|c|c|c|c|}
\hline Intervention & Fibre & Dose; Duration of the study & $\begin{array}{l}\text { Experimental } \\
\text { Design }\end{array}$ & Animal/subjects & Effects & Ref \\
\hline \multirow[t]{2}{*}{$\begin{array}{l}\text { Blood } \\
\text { Glucose }\end{array}$} & $\begin{array}{l}\text { Alginate } \\
\text { fiber }\end{array}$ & $\begin{array}{c}5.0-\text { g sodium } \\
\text { Alginate supplement } \\
\text { (algae isolate, } 75 \% \text { soluble } \\
\text { fiber); for two days }\end{array}$ & $\begin{array}{c}\text { Randomized, } \\
\text { Placebo controlled }\end{array}$ & $\begin{array}{c}\text { Seven men with type } \\
2 \text { diabetes; mean age } \\
\text { of } 53 \mathrm{yr}\end{array}$ & $\begin{array}{c}\text { Significantly reduced the } \\
\text { postprandial rise in blood } \\
\text { glucose }(P<0.05) \text { and in serum } \\
\text { insulin }(P<0.02) \text { by } 31 \% \& 42 \% \text {, } \\
\text { resp. }\end{array}$ & 89 \\
\hline & Soy hulls & $\begin{array}{l}26 \mathrm{~g} \text { of soy hulls which } \\
\text { Incorporated into } 7 \text { slices of } \\
\text { bread daily; for } 4 \text { weeks }\end{array}$ & $\begin{array}{c}\text { Randomized, } \\
\text { double-blind, } \\
\text { placebo controlled }\end{array}$ & $\begin{array}{c}10 \text { subjects ( } 5 \text { male } \\
\& 5 \text { female) with type } \\
2 \text { diabetes; mean age } \\
\text { of } 65 \pm 5.9 \mathrm{yr}\end{array}$ & $\begin{array}{c}\text { Significantly improved the } \\
\text { glucose score }(P<0.05) \& \text { the } \\
\text { total area under the glucose } \\
\text { curve }(P<0.05) \text { by } 6.7 \% \& 7.1 \% \text {, } \\
\text { resp. }\end{array}$ & 90 \\
\hline
\end{tabular}

Hypocholesterolemic effect: Hypertension is highly associated with hypercholesterolemia, where a lowering in cholesterol levels has been found to lower blood pressure. In a study evaluating the influence of Prebiotics on cholesterol, Mortensen et al. administered a purified diet with $10 \%$ of long-chained fructans into male mice for 16 weeks ${ }^{91}$. The control was not fed any Prebiotics. The study involved 40 male mice and the results showed that the supplementation of fructans significantly reduced blood cholesterol by 29.7\% $(P<0.001)$, LDL-cholesterol concentration by $25.9 \% \quad(P<0.01)$, IDL-cholesterol level by $39.4 \%$ $(P<0.001)$ and VLDL-cholesterol concentration by $37.3 \% \quad(P<0.05)$ compared to the control group. 
Hypertriglyceridemia is often associated with a Prebiotics have been found to reduce hepatic moderate hyperglycemia and insulinemia ${ }^{92}$, and triacylglycerol.

TABLE 5: IN VIVO- TRIALS SHOWING ASSOCIATION BETWEEN PREBIOTICS \& THEIR EFFECT ON LIPID PROFILE

\begin{tabular}{|c|c|c|c|c|c|c|}
\hline Intervention & Fibre & Dose; Duration of study & Experimental Design & Animal/ Subjects & Effects & Ref \\
\hline \multirow[t]{2}{*}{ Lipid Profile } & Pectin & $\begin{array}{l}75 \text { g citrus pectin daily; } \\
\text { for four weeks }\end{array}$ & $\begin{array}{c}\text { Randomized, } \\
\text { Placebo controlled }\end{array}$ & $\begin{array}{c}\text { Six male adult } \\
\text { hypercholesterolemi } \\
\text { c } \\
\text { mini pigs }\end{array}$ & $\begin{array}{c}\text { 67.1\% decrease in VLDL- } \\
\text { cholesterol } \\
(P<0.05) ; 41.1 \% \\
\text { decrease in LDL cholesterol } \\
(P<0.05) ; 49.4 \% \text { decrease in } \\
\text { total serum cholesterol }(P<0.05)\end{array}$ & 93 \\
\hline & $\begin{array}{l}\text { Fiber } \\
\text { (Plantago } \\
\text { ovata } \\
\text { husk) }\end{array}$ & $\begin{array}{l}10.5 \text { g Plantago } \\
\text { ovata husk daily; for } \\
\text { eight weeks }\end{array}$ & $\begin{array}{c}\text { Randomized, } \\
\text { crossover, placebo } \\
\text { controlled, single- } \\
\text { blind }\end{array}$ & $\begin{array}{l}\text { Twenty-eight men } \\
\text { with myocardial } \\
\text { infarction or stable } \\
\text { angina }\end{array}$ & $\begin{array}{c}6.7 \% \text { decrease in } \\
\text { plasma } \\
\text { triacylglycerol } \\
(P<0.02), 6.7 \% \\
\text { increase in } \mathrm{HDL} \text { cholesterol } \\
\text { concentrations } \\
(P<0.006) ; 10.6 \% \\
\text { decrease in the total cholesterol } \\
/ \mathrm{HDL} \text { ratio }(P<0.002) ; 14.2 \% \\
\text { decrease in } \mathrm{LDL} / \mathrm{HDL} \text { ratio } \\
(P<0.003)\end{array}$ & 94 \\
\hline
\end{tabular}

Functional Food Ingredients ${ }^{95}$ : As is the case with other dietary fibers, Prebiotics, like Inulin and oligofructose, are resistant to digestion in the upper part of the intestinal tract and are subsequently fermented in the colon. They have a bulking effect due to the increase in microbial biomass that results from their fermentation.

From a quantitative point of view, the bulking effect, expressed as the increase in daily fecal mass, has been reported to vary between 1.5 and $2 \mathrm{~g} / \mathrm{g}$ of ingested Inulin or oligofructose 2330 38, Prebiotics also belong to other categories of "functional food ingredients", which, by reference to the European consensus", should have unique features such as: being part of conventional or everyday foods, to be part of the normal/usual diet, being composed of natural (as opposed to synthetic) components, sometimes in increased concentrations or present in foods that would not normally supply them, and having a positive effect on target function(s) that may enhance wellbeing and health and/or reduce the risk of disease.

Immunomodulatory effects: Only few studies so far have investigated the Immunomodulatory effects of Inulin (IN)/Oligo fructose (OF) in humans. Recently, 2 clinical trials reported the therapeutic outcome of a prebiotic and synbiotic treatment in subjects with ulcerative colitis and Crohn's disease ${ }^{96}$. In a small randomized, double-blinded controlled trial including subjects with ulcerative colitis, the supplementation with B. longum, IN, and OF resulted in an improvement of the full clinical appearance of chronic inflammation. Further, intestinal mRNA levels of the proinflammatory cytokines interleukin (IL)-1b and tumor necrosis factor$\alpha$ were significantly reduced in synbiotic-treated subjects, whereas no significant differences were seen for the immunoregulatory cytokine IL-10 ${ }^{97}$.

In summary, only few human studies so far have investigated the effects of OF alone on the immune system. The currently available data suggest that the oral intake of IN/OF may modulate the immune system in humans. More human studies including doseresponse studies with Prebiotics such as IN/OF are needed, with a special focus on the GALT.

Hepatic Encephalopathy: Substances derived from the metabolism of the gut flora involved in the pathogenesis of hepatic encephalopathy $98,99,100$. The therapeutic efficacy of Lactulose has been demonstrated in RCTs. The side effects calculated from 18 studies concerning 298 patients were the following: flatulence $18 \%$, diarrhoea $14.5 \%$, and abdominal pain $13 \%{ }^{100}$.

The possible mechanisms of action include stimulation of bacterial growth, incorporation of ammonia into bacterial proteins, colon acidification, laxative effect, and possibly a shift in production of medium chain fatty acids to short chain fatty acids ${ }^{98}$. 
Colon Cancer: Fermentation reduces colonic $\mathrm{pH}$, and may reduce the 7-dehydroxylation of primary bile salts. A role of carbohydrate fermentation in colon cancer prevention has thus been hypothesized ${ }^{101}$ and studies in animal models have been encouraging. Several studies have shown that Lactulose administration to healthy volunteers $(40-60 \mathrm{~g} / \mathrm{d})$ lowered fecal concentrations of secondary bile salts ${ }^{102,103}$. However, in one study, administration of $60 \mathrm{ml}$ of Lactulose/d for 12 weeks did not influence crypt cell proliferation assessed in rectal biopsies ${ }^{104}$. Roncucci et al., reported in 1993 that Lactulose decreased the recurrence rate of colon adenomas ${ }^{105}$. Two hundred and fifty five patients with colon adenomas were randomized after removal of the adenomas to receive vitamins, Lactulose $(20 \mathrm{~g} / \mathrm{d})$ or no treatment.

Clinical Studies: Prebiotics like Inulin and Oligofructose have been shown to effect on calcium bioavailability. In adult humans, it appears that as long as the right methodology is used, it is possible to see an improvement of intestinal calcium absorption after Inulin-type fructans consumption ${ }^{106}$.

Moreover; such molecules did not alter this process in small intestine, probably because the modulation of mineral absorption by fructans originates mainly in the colon. This is why Ellegard et al., have shown that they do not affect mineral digestion in volunteers with an ileostomy, even though another explanation for the lack of effect in such patients could be an increased transit rate, eliciting reduced opportunities of Inulin type fructans to stimulate the fermentation process 107.

In a randomized double-blind crossover trial in 12 postmenopausal women, Tahiri et al., failed to show an effect of oligofructose consumption $(10 \mathrm{~g} / \mathrm{d}$ for 5 wk) on calcium absorption. However, the length of menopause was quite different among subjects: 8.36 $7.1 \mathrm{y}$. This corresponds to huge differences in terms of bone metabolism, and this could explain the lack of any significant effect ${ }^{108}$.

If Inulin-type fructans have failed to modulate calcium absorption during the first $5 \mathrm{y}$ after the onset of menopause, they appear to be efficient, later in life, probably because hormonal changes occurring during menopause become less important, leaving some room for other mechanisms of regulation. However, it is important to know if the extra absorbed calcium is deposited in bones. For that purpose, long term studies are needed.

Developing Prebiotics for Specific Probiotic Strains: Prebiotic structure, including chain length, branching, linkage types and the presence of mixtures of different molecules can affect the fermentation specificity of these compounds 109,110 . As such, small molecular differences in prebiotic structure may induce significant changes in physiological functions. For example, many Fructo-oligosaccharide products are available and it is apparent that products with higher molecular weight may be more slowly fermented and thus persists for longer in the colon.

Combinations of Inulin (DP 10-65) and oligofructose (DP 2-8) may elicit synergistic effects. If it were possible to match Prebiotics with probiotic strains, the physiological benefits may be enhanced ${ }^{111}$. Alternatively, probiotic strains might be selected for their ability to generate prebiotic oligosaccharides, which are then preferentially utilized by the producing probiotics $112,113,114$.

\section{Synbiotics \& Health Benefits:}

Pediatric Surgery: Kanamori et al., have reported long term efficacy of synbiotic therapy in pediatric patients under surgery for short bowel syndrome that showed repeated episodes of refractory enteritis and bacteremia since birth and Tracheoesophageal fistula 115,116 . For probiotics, live bacterial preparations of Bifidobacterium breve strain yakult and Lactobacillus casei strain Shirota were used and galactooligosaccharides were supplemented as probiotics.

A high viable probiotic bacterial content was detected in the patients' faeces, the intestinal bacterial flora was improved and the titre of harmful microorganism, Pseudomonas aeruginosa and Candida were reduced. As the intestinal bacterial flora was improved by synbiotic therapy, intestinal peristalsis recovered, intestinal expansion was reduced, and the nutritional condition improved as reflected by gain in body weight. 
Digestive Organ Surgery: Rayes et al., compared postoperative complication among groups treated with - (a) antibiotics for intestinal bacterial eradication; (b) synbiotics and (c) killed lactic acid bacteria, in patients with liver transplantation ${ }^{117}$. Lactobacillus plantarum 299 as a probiotic and oats as a prebiotic were administered to the synbiotic therapy for 12 days. The incidence of postoperative infections by discharge was 48, 13 and $34 \%$ in (a), (b) and (c) group, respectively, showing that the incidence was significantly lower in the intestinal bacterial eradication group ${ }^{118}$.

When 4 species of Lactic acid bacteria and 4 types of bacteria were combined in synbiotics after liver transplantation, the incidence of postoperative infection s was further reduced to $3 \%$ suggesting that synbiotic therapy was capable of reducing the incidence of postoperative infection that could not be completely checked by antibiotics treatment for control of intestinal bacteria.

Systemic Inflammatory Response Syndrome (SIRS): For emergency treatment, the control of marked systemic inflammatory reactions in response to severe injuries and burns is important. A new concept of inflammatory reaction, systemic inflammatory response syndrome has recently been proposed by a joint meeting of the American college of chest physicians and society of critical care ${ }^{119}$. SIRS represents systemic inflammatory reactions to stresses, and is defined as conditions showing abnormalities in 2 or more of the following 4 body systems (Body temperature, heart rate, respiratory rate and blood cell count. Shimizu et al., have investigated fecal microflora in SIRS patients considering disturbance of intestinal microflora in SIRS patients considering disturbance of intestinal flora accompanied by infection and intestinal flora and found that intestinal microflora was markedly disturbed in SIRS patients ${ }^{120}$.

Severe Acute Pancreatitis: Forty-five patients were supplemented from a time point in the disease process defined as early as possible with the one $L A B / o n e$ fibre formula containing either live or heat-killed $L A B{ }^{121}$. The study was interrupted when repeat statistical analysis demonstrated statistically significant differences in infection rate between the two groups. At that time, 22 patients had received treatment with live and 23 with heat-killed Lb plantarum 299. Infected pancreatic necrosis and abscesses were seen in $1 / 22$ (4.5\%) in the live LAB group and in $7 / 23(30 \%)$ in the heat-inactivated group ( $P$ 1/4 0:023). The only patient in the live LAB group, who developed infection, had signs of urinary infection on the 15th day, e.g. at a time when he had not received treatment during the last eight days. The length of stay was considerably shorter in the live LAB group (13.7 days vs. 21.4 days), but the limited size of the material did not allow statistical significance to be reached.

Liver Transplantation: The 30-day infection rate after liver transplantation is usually above $50 \%$; the most recent study reports a 30 -day morbidity of $86 \%$ despite or eventually due to extensive and multiple treatment with antibiotics (selective bowel decontamination) ${ }^{122}$. Two randomized studies were conducted in liver transplant patients in collaboration with the University of Berlin. When the one LAB/one fibre composition was supplied, a 30 day infection rate of $13 \%$ was observed compared to $34 \%$ with heat killed LAB and $48 \%$ with selective decontamination. The infection rate was in a second study using the four LAB/four fibre composition further reduced to only $3 \%$ (1/33 patients suffered a slight urinary infection) compared to $51 \%$ in the group treated with only fibres ${ }^{123}$.

Chronic Liver Disease: Pro- and Prebiotics (synbiotics) have the ability to reduce the production and absorption of endotoxin in the intestine, and to downregulate production of pro-inflammatory cytokines, such as TNF- $\alpha$. In a study in collaboration with University of Sidney we recently observed that in vitro TNF- $\alpha$ production by peripheral blood mononuclear cells, in response to stimulation by endotoxin or Staph aureus enterotoxin B, is reduced by a median $46 \%$ (range: $8-67 \%$ ) in comparison to pre-supplementation levels in $8 / 11(72.7 \%)$ cirrhotic patients supplied with the four $L A B /$ four fibre composition ${ }^{124}$.

In another study in chronic liver disease either the four $\mathrm{LAB} /$ four fibre formula, only the four fibres a placebo consisting in non-fermentable, non absorbable fibre was supplied daily during one month ${ }^{125}$. Significant decreases in the gut content of Escherichia coli, Staphylococcus and Fusobacterium, but not Pseudomonas and Enterococcus, were observed. Ammonia/s, levels of endotoxin/s and ALT/s fell 
significantly in both treatment groups and were accompanied by significant improvements in psychometric tests and in degree of encephalopathy. Supply of synbiotics to patients with various acute and chronic conditions is almost always well tolerated and has no adverse events or adverse changes in general clinical state of the patients.

Synbiotic treatment capable to down regulate the expression of Toll-like receptors and reduce the production of TNF- $\alpha$ seems to have the potential to be a cheap and powerful tool for both long-term treatment of patients with chronic diseases such as liver disease and for treatment of patients with various acute conditions. Efforts must continue to find the most powerful $L A B$ and the most powerful fibres or combinations thereof.

\section{REFERENCES:}

1. Eamonn M, Quigley M: Prebiotics and Probiotics; Modifying and mining the microbiota. Pharmacological research 2010; 61:213218

2. McNaught CE, MacFie J: Probiotics in clinical practice: a critical review of the evidence. Nutrition research 2001; 21:343-353

3. Fuller R: Probiotics in man and animals. J Appl Bacteriol 1989; 66:365-378

4. Collins MD, Gibson GR: Probiotics, Prebiotics and Synbiotics: approaches for modulating the microbial ecology of the gut. Am J Clin Nutr 1999; 69(S):1025S-1027S

5. Weiss G, Christensen HR, Zeuthen LH, Vogensen FK, Jakobsen M, Frokiaer $\mathrm{H}$ : Lactobacilli and Bifidobacteria induce differential interferon- $\beta$ profiles in dendritic cells. Cytokine(Article in press)

6. Penner R, Fedorak RN, Madsen KL: Probiotics and Neutraceuticals: non-medical treatments of gastrointestinal diseases. Current opinion in pharmacology 2005; 5:596-603

7. Grimoud J, Durand H, Souza SD, Monsan H, Quarne F, Theodorou $\checkmark$ et al: In vitro screening of Probiotics \& Synbiotics according to anti-inflammatory \& anti-proliferative effects. International Journal Of Food Microbiology 2010; 144:42-50

8. Borchers AT, Selmi C, Meyers FJ, Keen CL, Gershwin ME: Probiotics and Immunity. J Gastroenterol 2009; 44:26-46

9. Gibson GR, Roberfroid MB: Dietary modulation of the human colonic microbiota: introducing the concept of Prebiotics. Journal of Nutrition 1995; 125:1401-1412

10. Scantlebury-manning T, Gibson GR: Prebiotics. Best practice and research clinical Gastroenterology 2004; 18:287-298

11. Roberfroid MB: Prebiotics and Synbiotics: concepts and nutritional properties. British Journal of Nutrition 1998; 80:S197S202

12. Sartor RB: Therapeutic manipulation of the intestinal microflora in Inflammatory Bowel Diseases: antibiotics, Probiotics and Prebiotics. Gastroenterology 2004; 126:1620-1633

13. Iannitti T, Palmieri B: Therapeutical use of Probiotic formulations in clinical practice. Clinical Nutrition 2010; 29:701-725

14. Patterson JA, Burkholder KM: Application of Prebiotics and Probiotics in poultry production. Poultry Science 2003; 82:627-631

15. Rastall RA, Maitin V: Prebiotics and Synbiotics: towards the next generation. Current Opinion In Biotechnology 2002; 13:490-496
16. Bengmark S: Bioecological control of the gastrointestinal tract: the role of flora and supplemented Probiotics and Synbiotics. Gastroenterology clinics Of North America 2005; 34(8):413-436

17. Bengmark $S$, Martindale R: Prebiotics and Synbiotics in clinical medicine. Nutrition In Clinical Practice 2005; 20: 244-261

18. Geier MS, Butler RN, Howarth GS: Inflammatory Bowel Disease: current insights into pathogenesis and new therapeutic options; Probiotics, Prebiotics and Synbiotics. International Journal of Food Microbiology 2007; 115:1-11

19. Collins MD, Gibson GR: Probiotics, Prebiotics and Synbiotics: approaches for modulating the microbial ecology of the gut. Am J Clin Nutr 1999; 69(Suppl):1052S-1057S

20. Hanauer SB: Inflammatory Bowel Disease: Epidemiology, pathogenesis and therapeutic opportunities. Inflammatory Bowel Diseases 2005; 12(suppl.1):S3-S9

21. Kruis W, Schutz E et al: Double blind comparison of an oral Escherichia coli preparation and mesalazine in maintaining remission of ulcerative colitis. Aliment Pharmacol Ther 1997; 11:853-858

22. Malin $M$, Suomalainen et al: Promotion of IgA response in patients with Crohn's disease by oral bacteriotherapy with Lactobacillus GG. Ann Nutr Metab 1996; 40:137-145

23. Gienchitto $P$, Rizzello $F$ et al: Oral bacteriotherapy as maintenance treatment in patients with chronic pouchitis; a double placebo controlled trial. Gastroenterol 2000; 119: 305-309

24. Zhang L, Li N, Caicedo R, Neu J: Alive and dead Lactobacillus Rhamnosus GG decrease tumor necrosis factor-alpha-induced interleukin-8 production in caco-2 cells. Journal Of Nutrition 2005; 135:1752-1756

25. Ruiz PA, Hoffmann M, Szcesny S, Blaut M, Haller D: Innate mechanisms for Bifidobacterium Lactis to activate transient proinflammatory host responses in intestinal epithelial cells after the colonization of germ-free rats. Immunology 2005; 115:441-450

26. Buller HA, Grand RJ: Lactose Intolerance. Annual Reviews In Medicine 1990; 41:141-148

27. Scrimshaw TM, Murray EB: The acceptability of milk and milk products in populations with a high prevalence of Lactose intolerance. American Journal Of Clinical Nutrition. 1988; 48(Suppl):1079S-1159S

28. Chorawala MR, Oza PM, Shah GB: Probiotics, Prebiotics, Synbiotics: A Health Benefit Supplement. Research Journal Of Pharmaceutical, Biological and Chemical Sciences 2011; 2(3):11011111

29. Lu L, Walker WA: Pathologic and physiologic interactions of bacteria with the gastrointestinal epithelium. Am J Clin Nutr 2001; 73:S1124-30

30. Santosa S, Farnworth E, Jones PJ: Probiotics and their potential health claims. Nutr Rev 2006; 64:265-274

31. Aureli P, Capurso L, Castellazzi AM, Clerici M, Giovannini M, Morelli $L$ et al: Probiotics and health: An evidence-based review. Pharmacological Research 2011; 63:366-376

32. Deshpande G, Rao S, Patole S, Bulsara M: Updated meta-analysis of Probiotics for preventing necrotizing enterocolitis in preterm neonates. Pediatrics 2010; 125:921-930

33. Guarino A, Canani RB et al: Oral bacterial therapy reduces the duration of symptoms and of viral excretion in children with mild diarrhoea. J Pediatr Gastroenterol Nutr 1997; 25:516-519

34. DuPont HL, Ericsson CD: Prevention and treatment of Traveller's diarrhoea. New Engl J Med 1993; 25: 1821-1827

35. Black FT, Andersen PL et al: Prophylactic efficacy of Lactobacilli on Traveller's diarrhoea. Ann Med 1990; 22(1):53-56

36. Impallomeni M, Gallerly NP et al: Increased risk of diarrhoea caused by Clostridium Difficile in elderly patients receiving Cefotaxime. Br Med J 1995; 331:1345-1346 
37. Vanderhoof JA, Whitney DB et al: Lactobacillus GG in the prevention of antibiotic associated diarrhoea in children. J Pediatr 1999; 135:564-568

38. Heyman M, Desjeux JF: Significance of intestinal food protein transport. Gastroenterol Nutr 1992; 15:48-57

39. Kirjavainen PV, Gibson GR: Healthy gut microflora and allergy: Factors influencing development of the microbiota. Ann. Med. 1999; 32:288-292

40. Majamaa H, Isolauri E: Probiotics: A novel approach in the management of food allergy. J allergy Clin. Immunol. 1997; 99: 179-185

41. Kirjavainen PV, EINezami HS, Salminen SJ, Ahokas JT, Wright PF: Effects of orally administered viable Lactobacillus rhamnosus GG and Propionibacterium freudenreichii subsp. Shermanii JS on mouse lymphocyte proliferation. Clin. Diag. Lab. Immunol. 1999; 6:799-802

42. Kaur IP, Chopra k, Saini A: Probiotics: Potential pharmaceutical applications. European Journal Of Pharmaceutical Sciences 2002; 15:1-9

43. Taranto MP, Medici M, Perdigon G, Ruiz holgado AP, Valdez GP: Evidence for hypocholesterolemic effect of Lactobacillus reuteri in hypocholesterolemic mice. J. Dairy Sci. 1998; 81:2336-2340

44. Hirayama K, Raftar J: The role of Probiotic bacteria in cancer prevention. Microbes and infection 2000; 2: 681-686

45. Tavan E, Cayuela C, Antoine JM, Cassand P: Antimutagenic activities of various Lactic acid bacteria against food mutagens: Heterocyclic amines. Journal Of Dairy Research 2002; 69:335-341

46. Lo PR, Yu RC, Chou CC, Huang EC: Determinations of the antimutagenic activities of several Probiotic Bifidobacteria under acidic and bile conditions against benzo[ $\alpha$ ] pyrene by a modified Ames test. International Journal Of Food Microbiology 2004; 93:249-257

47. Rafter J: Lactic acid bacteria and cancer: Mechanistic perspective. British Journal Of Nutrition 2002; 88(Suppl):S89-S94

48. O'Boyle CJ, MacFie J et al: Microbiology of bacterial translocation in humans. Gut 1998; 42:29-35

49. Cocconier MH, Lievin V, Lorrot M, Servin AL: Antagonistic activity of Lactobacillus acidophilus LB against intracellular Salmonella enterica serovar typhimurium infecting human enterocyte-like Caco-2/TC-7 cells. Applied And Environmental Biology 2006; 66:1152-1157

50. Lievin -Le MV, Amsellem $R$, Servin AL, Cocconier $M H$ : Lactobacillus acidophilus (strain LB) from the resident adult human gastrointestinal microflora exerts activity against brush border damage promoted by diarrhoeagenic Escherichia coli in human enterocyte-like cells. Gut 2002; 50:803-811

51. Plummer $M$, Franceschi $S$, Munoz N: Epidemiology of gastric cancer. IARC Scientific Publications 2004; 157:311-326

52. Sgouras DN, Panayiotopoulos EG, Martinez-Gonzalez B, Petraki K, Michopoulos S, Mentis A: Lactobacillus Johnsonii La1 attenuates Helicobacter-pylori associated gastritis and reduces level of proinflammatory chemokines in C57BL/6mice. Clinical And Diagnostic Laboratory Immunology 2005; 12:1378-1386

53. Sgouras D, Maragkoudakis P, Petraki K, Martinez-Gonzalez B, Eriotou $E$, Michopoulos $S$ et al: In vitro and In vivo inhibition of Helicobacter pylori by Lactobacillus casei strain Shirota . Applied And Environmental Microbiology 2004; 70:518-526

54. Wang KY, Li SN, Liu CS, Perng DS, Su YC, Wu DC et al: Effects of ingesting Lactobacillus- and Bifidobacterium-containing yogurt in subjects with colonized Helicobacter pylori. American Journal Of Clinical Nutrition 2004; 80:737-741

55. Linsalata M, Russo F, Berloco P, Caruso ML, Matteo GD, Cifone MG et al: The influence of Lactobacillus brevis on ornithine decarboxylase activity and polyamine profiles in Helicobacterpylori infected gastric mucosa. Helicobacter 2004; 9:165-172

56. Gotteland M, Cruchet S: Suppressive effect of frequent ingestion of Lactobacillus johnsonii La1 on Helicobacter pylori colonization in asymptomatic volunteers. The Journal of Antimicrobial Chemotherapy 2003; 51:1317-1319

57. Perdigon G, Alvarez S, Medina M, Vintini E, Roux E: Influence of the oral administration of Lactic acid bacteria on IgA producing cells associated to bronchus. Int. J. Immunopathol. Pharmacol 1999; 12:97-102

58. Ramakrishna BS: Probiotic-induced changes in the intestinal epithelium: Implications in gastrointestinal disease. Tropical Gastroenterology 2009; 30(2):76-85

59. Lirussi F, Mastropasqua E, Orando S, Orlando R: Probiotics for non-alcoholic fatty liver disease and/or steatohepatitis. Cochrane Database syst. Rev. 2007; (1):CD005165

60. Lata J, Novotny I, Pribramska V, Jurankova J, Fric P, Kroupa R et al: The effect of Probiotics on gut flora, level of endotoxin and childPugh score in cirrhotic patients: results of a double-blind randomized study. Eur. J. Gastroenterol. Hepatol. 2007; 19:11111113

61. Zuccotti GV, Meneghin F, Raimondi C, Dilillo D, Agostoni C, Riva E, Giovannini M: Probiotics in clinical practice: an overview. J. Int. Med. Res 2008; 36(Suppl1)

62. Reid G, Bruce A: Urogenital infections in women: can Probiotics help? Postgrad. Med. J. 2003; 79:428-432

63. Czaja CA, Stapleton AE, Yarova-Yarovaya Y, Stamm WE: Phase I trial of Lactobacillus crispatus vaginal suppository for prevention of recurrent urinary tract infection in women. Infect. Dis. Obstet. Gynecol 2007; 2007:35387

64. Kecskes G, Belagyi T, Olah A: Early jejunal nutrition with combined pre- and Probiotics in acute pancreatitis-prospective, randomized, double-blind investigations. Magy Seb 2003; 56:3-8

65. Olah A, Belagyi T, Issekutz A, Gamal ME, Bengmark S: Randomized clinical trial of specific Lactobacillus and fibre supplement to early enteral nutrition in patients with acute pancreatitis. Br. J. Surg. 2002; 89:1103-1107

66. Rautava S, Salminen S, Isolauri E: Specific Probiotics in reducing the risk of acute infections in infancy-a randomized, double-blind, placebo-controlled study. Br. J. Nutr. 2009; 101:1722-1726

67. Leyer GJ, Li s, Mubasher ME, Reifer C, Ouwehand AC: Probiotic effects on cold and influenza - like symptom incidence and duration in children. Pediatrics 2009; 124:e172-179

68. De vrese $M$, Winkler $P$, Rautenberg $P$, Harder $T$, Noah $C$, Laue $C$ et al: Probiotic bacteria reduced duration and severity but not the incidence of common cold episodes in a double blind, randomized, clinical trial. Vaccine 2006; 24:6670-6674

69. Boge $T$, Remigy $M$, Vaudaine S, Tanguy J, Bourdet-sicard R, Van der WS: A Probiotic fermented dairy drink improves antibody response to influenza vaccination in the elderly in two randomized controlled trials. Vaccine 2009; 27:5677-5684

70. Guillemard E, Tondu F, Lacoin F, Screzenmeir J: Consumption of a fermented dairy product containing the Probiotic Lactobacillus casei DN-114001 reduces the duration of respiratory infections in the elderly in two randomized controlled trials. Br. J. Nutr. 2010; 103:58-68

71. Sorokulova IB, Beliavskaia VA, Masycheva VA, Smirnov VV: Recombinant Probiotics: problems and prospects of their use for medicine and veterinary practice. Vestn. Ross. Akad. Med. Nauk. 1997; 3:46-49

72. Sorokulova IB: The safety and reactogenicity of the new Probiotic Subalin for volunteers. Mikrobiol.z. 1998; 60:43-46 
73. Osipova IG, Sorokulova IB, Tereshkina NV, Grogor'eva LV: Safety of bacteria of the genus Bacillus, forming the base of some Probiotics. Zh. Mikrobiol. Epidemiol. Immunobiol 1998; 6:68-70

74. Madsen KL, Doyle JS, Jewell LD, Tavernini MM, Fedorak RN: Lactobacillus species prevents colitis in interleukin gene 10 deficient mice. Gastroenterology 1999; 116:1107-1114

75. Videla S, Vilaseca J, Antolin M, Garcia-lafuente A, Gaurner F, Crespo $E$ et al: Dietary Inulin improves Distal colitis induced by Dextran sulfate sodium in the rat. Am. J. Gastroenterol 2001; 96:1486-1493

76. Hoentjen F, Welling GW, Harmsen HJ, Zhang X, Snart J, Tannock GW et al: Reduction of colitis by Prebiotics in HLA-B27 transgenic rats is associated with microflora changes and Immunomodulation. Inflamm. Bowel Dis. 2005; 11:977-985

77. Lara-villoslada F, Debras E, Neeto A, Coecha A, Galvez J, LopezHuertas $\mathrm{E}$ : Oligosaccharides isolated from goat milk reduce intestinal inflammation in a rat model of Dextran sulfate sodiuminduced colitis. Clin. Nutr. 2006; 25:477-488

78. Rumi G, Tsubouchi R, Okayama M, Kato S, Mozsik G, Takeuchi K: Protective effect of Lactulose on Dextran sulfate sodium-induced colonic inflammation in rats. Dig. Dis. Sci. 2004; 49:1466-1472

79. Fakuda M, Kanauchi O, Araki Y, Andoh A, Mitsuyama K, Takagi K et al.: Prebiotic treatment of experimental colitis with germinated barley foodstuff: a comparison with Probiotic or antibiotic treatment. Int. J. Mol. Med. 2002; 9:65-70

80. Kanauchi O, Mitsuyama K, Homma T, Takahama K, Fujiyama Y, Andoh $A$ et al: Treatment of ulcerative colitis patients by long term administration of germinated barley foodstuff: multi-centre open trial. Int. J. Mol. Med. 2003; 12: 701-704

81. Hanai H, Kanauchi O, Mitsuyama K, Andoh A, Takeuchi K, Takayuki I et al: Germinated barley foodstuff prolongs remission in patients with ulcerative colitis. Int. J. Mol. Med. 2004; 13:643-647

82. Lindsay JO, Whelan K, Stagg AJ, Gobin P, Al-Hassi HO, Rayment N et al: Clinical microbiological, and immunological effects of Fructooligosaccharide in patients with Crohn's disease. Gut 2006; 55:348-355

83. He J, Streiffer RH, Whelton PK: Effect of Dietary fibre supplementation on blood pressure: A randomized double-blind placebo-controlled trial. J. Hypertens. 2004; 22:73-80

84. Burke V, Hodgson JM, Beilin LJ, Giangiulioi N, Rogers P, Puddey IB: Dietary protein and soluble fibre reduce ambulatory blood pressure in treated hypertensives. Hypertension 2001; 38:821-826

85. Eliasson K, Ryttig KR, Hylander B, Rossner S: Dietary fibre supplement in the treatment of mild hypertension: A randomized, double-blind, placebo-controlled trial. J. Hypertens 1992; 10:195199

86. Keenan JM, Pins JJ, Frazel C, Moran A, Turnquist L: Oat ingestion reduces systolic and diastolic blood pressure in patients with mild or borderline hypertension: a pilot trial. J. Fam. Pract. 2002; 51:369

87. Lee YP, Mori TA, Puddey IB, Sipsas S, Ackland TR, Beilin LJ: Effects of Lupin Kernel Flour-enriched bread on blood pressure: $A$ controlled intervention study. Am. J. Clin. Nutr. 2009; 89:776-772

88. Cani PD, Neyrinck AM, Fava F, Knauf C, Burcelin RG, Tuohy KM et al: Selective increases of Bifidobacteria in gut microflora improve High-fat-diet induced Diabetes in mice through a mechanism associated with Endotoxaemia. Diabetologia 2007; 50:2374232383

89. Torsdottir I, Alpsten M, Holm G, Sanberg AS, To-Ili J: A small dose of alginate-fiber effects of postprandial glycemia and gastric emptying in humans with diabetes. J Nutr. 1991; 121:795-799

90. Mahalko JR, Sandstead HH, Johnson LHK, Inman LF, Milne DB, Warner RC: Effect of consuming fiber from corn bran, soy hulls or apple powder on glucose tolerance and plasma lipids in type II diabetes. Am. J. Clin. Nutr. 1984; 39:25-34

91. Mortensen A, Poulsen M, Frandsen H: Effect of a long-chained fructans Raftiline HP on blood lipids and spontaneous atherosclerosis in low density receptor knockout mice. Nutr. Res. 2002; 22:473-480

92. Kok N, Roberfroid M, Delzenne N: Dietary oligofructose modifies the impact of fructose on Hepatic triacylglycerol metabolism. Metabolism 1996; 45:1547-1550

93. Ahrens F, Hagemeister H, Pfeuffer M, Barth CA: Effects of oral and intracecal pectin administration on blood lipids in minipigs. J. Nutr. 1986; 116:70-76

94. SolaR, Godas G, Ribalta J, Vallve JC, Girona J et al: Effects of soluble fiber (plantago ovate husk) on plasma lipids, lipoproteins and Apolipoproteins in men with ischemic heart disease. Am. J. Clin. Nutr. 2007; 85:1157-1163

95. Roberfroid $\mathrm{M}$ : Functional food concept and its application to Prebiotics. Digest. Liver Dis. 2002; 34(Suppl.2):S105-110

96. Seifert S, Watzl B: Inulin and Oligofructose: Review of Experimental data on immune modulation. The Journal of Nutrition 2007; 2563S-2567S

97. Furrie E, MacFarlane S, Kennedy A, Cummings JH, Walsh SV, O'Neil DA: Synbiotic therapy (Bifidobacterium longum/synergy 1) initiates resolution of inflammation in patients with active ulcerative colitis: a randomized controlled pilot trial. Gut 2005; 54:242-249

98. Clausen MR, Mortensen PB: Lactulose, Disaccharides and colonic flora. Clinical consequences. Drugs 1997; 53:930-942

99. Cordoba J, Blei AT: Treatment of Hepatic encephalopathy. Am. J. Gastroenterol. 1997; 9:1429-1439

100. Orlandi F, Brunelli E, Benedetti A, Macarri G: Clinical trials of Lactulose therapy in hepatic encephalopathy. In: Conn $\mathrm{H} \mathrm{O}$. Bircher J (Eds). Hepatic encephalopathy - management with Lactulose and related carbohydrates. East Lancing, Michigan: Medi-ed press, 1988:191-198

101. Van Munster IP, Nagengast FM: The role of carbohydrate fermentation in colon cancer prevention. Scand. J. Gastroenterol 1993; 28(Suppl 200):80-86

102. Nagengast FM, Hectors FM, Buys WA, Van Tongeren JH: Inhibition of secondary bile acid formation in the large intestine by Lactulose in healthy subjects of two different age groups. Eur. J. Clin. Invest. 1988; 88:56-61

103. Owen RW: Faecal steroids and colorectal carcinogenesis. Scand. J. Gastroenterol 1997; 32(Suppl 222):76-82

104. Rooney PS, Hunt LM, Clarke PA, Gifford KA, Hardcastle JA, Armitage NC: Wheat fibre, Lactulose and rectal mucosal proliferation in individuals with a family history of colorectal cancer. Br. J. Surg. 1994; 81:1792-1794

105. Roncucci L, Di Donato P, Carati et al: Antioxidant vitamins or Lactulose for the prevention of the recurrence of colorectal adenomas. Dis. Colon Rectum 1993; 36:227-234

106. Coxam V: Current data with Inulin-type Fructans and Calcium, Targeting bone health in adults. The Journal Of Nutrition 2007; 2527S-2533S

107. Ellegard L, Andersson H, Bosaeus I: Inulin and Oligofructose do not influence the absorption of cholesterol, and the excretion of cholesterol, $\mathrm{Fe}, \mathrm{Ca}, \mathrm{Mg}$ and Bile acids but increases energy excretion in man. A blinded controlled cross-over study in ileostomy subjects. Eur. J. Clin. Nutr. 1997; 51:1-5

108. Tahiri M, Tressol JC, Arnaud J, Bornet FR, Bouteloup-Demange C, Feillet-coudry $C$ et al: Effect of short-chain Fructo-oligosaccharides on intestinal calcium absorption and calcium status in postmenopausal women a stable-isotope study. Am. J. Clin. Nutr. 2003; 77:449-457 
109. Rycroft CE, Jones MR, Gibson GR, Rastall RA: A comparative study of the fermentation properties of prebiotic oligosaccharides. J. Appl. Microbiol. 2001; 91:878-887

110. Palframan R, Gibson GR, Rastall RA: Effect of $\mathrm{pH}$ and dose on the growth of gut bacteria on prebiotic carbohydrates in vitro. Anaerobe 2003; 8:287-292

111. Rastall RA, Maitin V: Prebiotics and Synbiotics: towards the next generation. Curr. Opin. Biotechnol. 2002; 13:490-498

112. Rabiu BA, Jay AJ, Gibson GR, Rastall RA: Synthesis and fermentation properties of novel Galacto-oligosaccharides by $\beta$ galactosidases from Bifidobacterium species. Appl. Env. Microbiol. 2001; 67:2526-2530

113. Tzortzis G, Goulas AK, Baillon MLA, Gibson GR, Rastall RA: In vitro evaluation of the fermentation properties of galactooligosaccharides synthesized by $\alpha$-galactosidases from Lactobacillus reuteri . Appl. Microbiol. Biotechnol. 2004; 64:106111

114. Mori H, Sato $\mathrm{Y}$, Taketomo N, Kamiyama T, Yoshiyama $\mathrm{Y}$, Meguro $\mathrm{s}$ et al: Isolation and structural identification of bifidogenic growth stimulator produced by Propionibacterium freudenreichii. J. Dairy Sci. 1997; 80:1959-1964

115. Kanamori Y, Sugiyama M, Hashizume K, Yuki N, Morotomi M, Tanaka R: Experience of long-term synbiotic therapy in seven short bowel patients with refractory enterocolitis. J. Pediatr. Surg 2004; 39:1686

116. Kanamori Y, Hashizume K, Kitano Y, Tanaka Y, Morotomi M, Yuki N et al: Anaerobic dominant flora was reconstructed by synbiotics in an infant with MRSA enteritis. Pediatr. Intr. 2003; 45:359

117. Rayes N, Seehofer D, Hansen S, Boucsein K, Muller AR, Serke AS: Early enteral supply of Lactobacillus and fiver versus selective bowel decontamination: a controlled trial in liver transplant recipients. Transplantation 2002; 74:123

118. Rayes N, Hansen S, Seehofer D, Muller AR, Serke S, Bengmark $\mathrm{S}$ :Early enteral supply of fiber and Lactobacilli versus conventional nutrition: a controlled trial in patients with major abdominal surgery. Nutrition 2002; 18:609

119. Robertson CM, Coopersmith CM: The systemic inflammatory response syndrome. Microbes. Infect. 2006; 8:1382

120. Shimizu K, Ogura H, Goto M, Asahara T, Nomoto K, Morotomi M et al: Altered gut flora and environment in patients with severe SIRS. J. Trauma 2006; 60:126

121. Olah A, Belagyi T, Issekutz A, Gamal ME, Bengmark S: Early enteral nutrition with specific Lactobacillus and fibre reduces sepsis in severe acute pancreatitis. Br. J. Surg. 2002; 89:1103-1107

122. Rayes N, Hansen S, Boucsein K, Seehofer D, Muller AR, Serke S: Early enteral supply of fibre and Lactobacilli Vs parenteral nutrition - a controlled in major abdominal surgery patients. Nutrition 2002; 18:609-615

123. Rayes N, Seehofer D, Theruvath T, Langrehr JM, Muller AR, Bengmark $S$ et al.: Combined preoperative enteral supply of bioactive Pre- and Probiotics abolishes post-operative bacterial infections in human liver transplantation - a randomized, doubleblind clinical trial , accepted for publication.

124. Riordan SM, Skinner N, Nagree A et al: Peripheral blood mononuclear cell expression of toll-like receptor $s$ and relation to cytokine levels in cirrhosis. Hepatology 2003; 37:1154-1164

125. Qing L, Zhong PD, Da KH et al: Synbiotic modulation of gut flora: effect on minimal hepatic encephalopathy in patients with liver cirrhosis, accepted for publication. 